\title{
Fractional Design Wizard: A computer program for cost-effective experimental research design
}

\author{
JOHANNES A. LANDSHEER \\ Utrecht University, Utrecht, The Netherlands \\ and \\ GODFRIED VAN DEN WITTENBOER \\ University of Amsterdam, Amsterdam, The Netherlands
}

\begin{abstract}
The computer program Fractional Design Wizard creates fractional factorial designs that are costeffective and especially useful for discarding irrelevant factors from a large number of possible candidates. The program is intended for researchers who are relativelynew to the field of fractional design and who want to acquaint themselves with the use of fractions for the reduction of large experimental designs. Fractional designs allow estimation of main effects, and sometimes two-way interactions, without one's having to examine all treatment conditions. The program needs Microsoft Windows 95 or better and $32 \mathrm{MB}$ of memory. In a step-by-step fashion, the user can specify the required properties of the fractional design. When there are more valid designs, the user can generate these successively. If necessary, the user can go back to diminish the requirements. The output can be copied, printed, and saved. The program generates all the information that is needed for the use and interpretation of fractional designs. A help file explains the use of the program and also the purpose, the analysis, and the interpretation of fractional designs. The program, which is written in Object Pascal, is available as freeware on www.fss.uu.nl/ms/hl/fracdes.htm.
\end{abstract}

Especially in the first stages of research, it is not always clear which of many possible factors are relevant. Inclusion of all factors results in enormous factorial designs, which can cause practical problems because of the large number of subjects involved. Fractional design offers a solution to this problem by reducing the number of factor combinations of a design and, therefore, treatments (or runs) and cases. There are two situations in which the use of fractional design is recommendable (Landsheer \& van den Wittenboer, 2000). The first is the elimination of possibly irrelevant factors from a large number of possible candidates. The second is the estimation of main factors and sometimes two-way interactions when higher order interactions can be considered negligible in designs with a large number of factors.

The reduction of a full design is accomplished by confounding effects. Effects that are confounded are noted as an equivalence, for instance $\mathrm{A}=\mathrm{B} * \mathrm{C} * \mathrm{E}=\mathrm{B} * \mathrm{D} * \mathrm{~F}=\mathrm{A} *$ $\mathrm{C} * \mathrm{D} * \mathrm{E} * \mathrm{~F}$, which means that main effect $\mathrm{A}$ is confounded with the two three-way effects BCE and BDF and with the five-way effect ACDEF. For the totality of these confounded effects, there is only one estimate of variance. When this estimate is not significant, the conclusion that all

Correspondence concerning this article should be addressed to J. A Landsheer, Utrecht University Faculty of Social Sciences, Department of Methodology and Statistics, P. O. Box 80140, NL3508TC Utrecht, The Netherlands (e-mail: j.a.landsheer@fss.uu.nl). confounded effects are negligible is warranted. When this estimate is significant, it can be considered to be an estimate of factor A, assuming that the higher order effects $\mathrm{BCE}, \mathrm{BDF}$, and ACDEF are negligible. Higher order effects can never be estimated when using a fractional design.

Most fractional designs allow all main factors to be tested, although in some cases, the two-way interaction effects can be estimated next to the main effects. The price to be paid is the impossibility of estimating higher order interaction effects. If these higher order interactions are assumed to be zero, they can be eliminated from the confounded effects, allowing for a valid estimation of the magnitude of main effects and possibly two-way interactions. Main effects are estimable when they are confounded only with higher order interactions, but not with each other. Twoway interactions can be estimated when they are confounded neither with each other nor with the main effects, but with only higher order interactions. The main effects and two-way interactions can be estimated, if the higher order interactions are known. In general, when the higher order effects are known in advance, they can be subtracted from the total of estimated variance. However, in most cases, the higher order effects are assumed to be zero.

Fractional design has evolved in the field of quality control. When a new product is made, there are many unknown possible shortcomings in the production process. Mesenbrink and Lu (1994), who studied the quality of a wavesoldering process, gave an example of such a study. In the 
social sciences, Berger and Magliozzi (1993) have applied fractional design in direct mail research. Fractional designs are also often applied in the field of consumer-choice research (Cestre \& Darmon, 1998; Kaul \& Rao, 1995).

Because fractional design is not commonly applied in the social sciences, the advantages and disadvantages of its use are not generally known. The main purpose of the program is to make fractional designs available for social science researchers. Because the use of fractional design is not without complications, a help file pays special attention to the usage of fractional design, the analysis of fractional design results, and the interpretation of the results.

Franklin (1985) published the algorithm for the generation of fractional designs, which forms the basis of the program. Turiel (1988) published a FORTRAN-program that implemented the algorithm. The latter program had a terminal-oriented interface that did not allow for the correction of user mistakes, and its documentation was limited. Moreover, the program had to be used on mainframes because of its generous usage of memory resources, unavailable to desktop computers in those days. The present program makes the program available for desktop users and tries to be helpful by providing a step-by-step interface. It also has a more generous allowance for user mistakes and corrections and has an extended help file that also includes a short introduction to fractional design itself.

Nachtheim (1987) discussed tools for computer-aided design of experiments. Some of the programs discussed offered the possibility of generating two-level fractional factorial designs. The present program offers a wider range of these designs, because it is not limited to two-level factors. Another relevant improvement is the interface, making the present program easier to use. More recently, SPSS (1997) offered a program for the cost-effective reduction of factorial designs. As such, Trial Run offers solutions in even the most difficult cases and is very complete for handling a huge number of different, often complicated designs. However, the program is not very easy to use. Moreover, because the program does not always provide correct information, it should be used with caution (Landsheer \& van den Wittenboer, 2000). The present program is more useful as an introduction to fractional design, although advanced users may want to use Trial Run for its provisions of other solutions besides fractional designs and especially when there is no fear of misinterpretation resulting from inadequate or incorrect information.

\section{FRACTIONAL DESIGN}

Fractional design is a systematic approach to limiting the number of cells (treatment combinations or runs) of a full factorial experimental design. The benefit of fractional design compared with a full factorial design is that costs can be sharply reduced by having a smaller design. The disadvantage of fractional design is that not all effects can be estimated. However, a fractional design is constructed in such a way that at least the main effects can be estimated.

For instance, in an experiment with six factors with two levels each (a $2^{6}$ design), there are 64 cells, and at least 64 runs are needed. The full design requires at least 64 subjects, with only a single subject for every treatment combination; however, in that case, it is not possible to estimate within-cell variance. Fractionating the design means that the design is partitioned into several equivalent parts, with each part requiring only a fraction of the number of subjects. For instance, one creates a design with four fractions of 16 runs each. The notation for such a design is $2^{(6-2)}$. With the fractional design, it is possible to use one of the four fractions with only 16 treatment conditions. With 32 subjects, there are two subjects in each cell. This number of subjects is half that of the full design, and it also allows for an estimate of within-group variance. In a fractional design, only a selection of the cells of the full factorial design is used. The systematic selection of treatment combinations (cells or runs) results in the combination of several effects, with only a single estimate available for the total amount of variance of these combined effects. This is called confounding. The effects that are combined are noted as an equivalence. See the example below.

Confounded effects of a $2^{(6-2)}$ design.

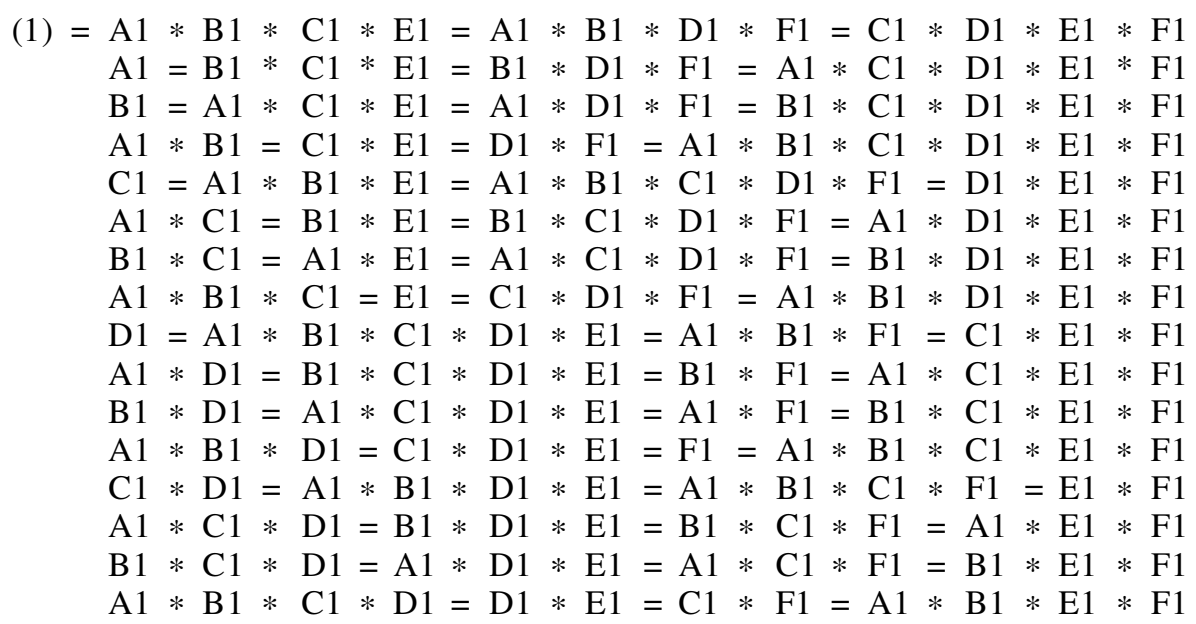


Here, the confounded effects are noted in the same way as in Fractional Design Wizard: The number after each factor indicates that it is concerned with an effect in a fractional design. In this design, all main effects are confounded only with interaction effects of three or more factors, whereas two-way interactions are confounded with each other but not with main effects. This means that the main effects can be estimated, if one assumes that all interactions of three or more factors are negligible. The two-way interactions cannot be estimated, since these are confounded with each other. However, when the main effects are estimated, it is not necessary to assume that the two-way interactions are zero.

The variances of confounded effects are summed, and a single estimate is available for the total amount of variance. For instance, main effect A1 can be estimated if the effects $\mathrm{B} 1 * \mathrm{C} 1 * \mathrm{E} 1, \mathrm{~B} 1 * \mathrm{D} 1 * \mathrm{~F} 1$ and $\mathrm{A} 1 * \mathrm{C} 1 * \mathrm{D} 1 * \mathrm{E} 1 * \mathrm{~F} 1$ are assumed to be zero. Alternatively, if the amount of variance attributable to three effects is known from previous research, the fourth effect can be estimated. If the total amount of variance of the confounded effects is zero, all effects must be zero, including the main effect. This makes the technique especially useful in a situation in which one wishes to eliminate possibly irrelevant factors from among many candidates.

There are nearly always various possibilities for fractionating a full design into equivalent parts. However, only fractional designs that allow for at least the estimation of main effects are considered to be useful. Effects that are not confounded with each other are called protected effects, and, in essence, these protected effects are estimable. Fractional Design Wizard allows the user to select these protected effects, although it is not always possible to find a valid fractional design with the desired properties.

\section{Notation}

In a fractional design, all main effects remain unsplit, each with the normal degrees of freedom. Main effects are all bound to unity, which is noted by Fractional Design Wizard as A1, B1, C1, and so on. Interaction effects of factors with three levels or more can be split into equivalent parts, each with a corresponding allotment of degrees of freedom. In a fractional design with factors of three levels, all interaction effects are split into parts, each with two degrees of freedom. For each effect (interaction effects as well as main effects), the first factor is always indexed with 1 . For instance, in a design with factors of three levels, the $\mathrm{A} \times \mathrm{B}$ effect ( $4 d f$ ) is split into two parts, which are noted as $\mathrm{A} 1 * \mathrm{~B} 1$ and $\mathrm{A} 1 * \mathrm{~B} 2$, each with $2 d f$. With two levels, all interaction effects have only a single degree of freedom and the interaction effects are not split. In general, in fractional designs with factors of $n$ levels, there are $n-1 d f$ for each main effect and $n-1 d f$ for each of the partitioned interaction effects. It is important to note that the indexes do not refer to levels, but that the effect notation refers to contrasts in the fractional design.

In general, fractional effects are noted by a combination of letters and digits, and most authors use superscripts
(Kempthorne, 1979; Winer, Brown, \& Michels, 1991). As Fractional Design Wizard uses text-only output, normal digits are used. Moreover, to make clear that every effect is an effect of a fractional design, one always uses a combination of a factor and a digit. For instance, in a $3^{(3-1)}$ design there are 13 effects, which are commonly noted as $\mathrm{A}, \mathrm{B}, \mathrm{C}, \mathrm{A} * \mathrm{~B}, \mathrm{~A} * \mathrm{~B} 2, \mathrm{~A} * \mathrm{C}, \mathrm{A} * \mathrm{C} 2, \mathrm{~B} * \mathrm{C}, \mathrm{B} * \mathrm{C} 2, \mathrm{~A} *$ $\mathrm{B} * \mathrm{C}, \mathrm{A} * \mathrm{~B} * \mathrm{C} 2, \mathrm{~A} * \mathrm{~B} 2 * \mathrm{C}$, and $\mathrm{A} * \mathrm{~B} 2 * \mathrm{C} 2$. These are noted in the text-only output of Fractional Design Wizard as A1, B1, C1, A $1 * \mathrm{~B} 1, \mathrm{~A} 1 * \mathrm{~B} 2, \mathrm{~A} 1 * \mathrm{C} 1, \mathrm{~A} 1 *$ $\mathrm{C} 2, \mathrm{~B} 1 * \mathrm{C} 1, \mathrm{~B} 1 * \mathrm{C} 2, \mathrm{~A} 1 * \mathrm{~B} 1 * \mathrm{C} 1, \mathrm{~A} 1 * \mathrm{~B} 1 * \mathrm{C} 2, \mathrm{~A} 1 *$ $\mathrm{B} 2 * \mathrm{C} 1$, and $\mathrm{A} 1 * \mathrm{~B} 2 * \mathrm{C} 2$. The digits do not refer to the levels, but are used to discriminate between the partitioned effects. The partitioned interaction effects are separate estimates of the unpartitioned interaction effect and, apart from that, they have no meaning.

\section{Fractional Design Analysis}

Many fractional designs can be analyzed with common analysis of variance (ANOVA) programs. For the estimation of main effects there are no special necessary provisions. In the case of designs with two-level factors, all interaction effects of fractional designs are also estimable with common ANOVA programs (Mendenhall, 1968). Only when the user wants to analyze fractional designs with factors of three levels or more, special provisions are necessary for the estimation of two-way interaction effects. Details on the calculation of effects when fractional designs are used can be found in Kirk (1993).

When a fractional design involves factors of three levels or more, all interaction effects are split into components. When the fractional design is constructed in such a way that some or all of the two-way interactions are estimable, the components of these two-way interactions require separate labeling. And, since the degrees of freedom of each interaction effect are equally divided over the fractionated interaction components, a program for the analysis of the interaction components has to attribute the correct degrees of freedom to each of the interaction components. Regrettably, a program for the ANOVA that could handle this situation gracefully is not generally available. Most common ANOVA programs are not equipped with the necessary options to handle these special requirements. However, in many cases, the analysis and interpretation of these partitioned interaction components are unnecessary.

\section{Computer Program Design}

The program is intended for researchers who want to become acquainted with the properties of fractional designs. The program is especially relevant for researchers of designs with a large number of factors, who may want to reduce the design without losing the possibility of testing all main effects. The largest design that can be fractionated by Fractional Design Wizard is a design with 10 factors of two levels.

The first objective of the program is to make a complicated arithmetic procedure available to researchers. The 
second objective of the program is to offer an easy-to-use interface. The general structure is more or less that of other so-called experts or wizards that are often used within the Windows working environment. This structure allows the user to make decisions on a step-for-step basis, providing no more than the necessary information for making the decision at hand. The user gives the necessary input in a total of eight dialog windows that are presented in a step-forstep fashion. Dialog windows that become superfluous are skipped, depending on the user's input. All dialog windows have a corresponding page in the accompanying help file. In most cases, user input is limited to valid values. If the user wants a design that requires too much of the memory resources, the user is warned and invited to reduce the design. The output is first presented on screen. The user can select, cut and paste the output for use in other programs, send it to the printer, or save it as a text-only file.

Requirements. The computer program requires a current desktop computer with Windows 95 (or a more recent version of this operating system), having a minimum of 32 MB of memory. It is provided with an installer, offering add-and-remove procedures common to Windows users. Fractional Design Wizard is written in Object Pascal within the Delphi programming environment. The main library is the Visual Component Library, a standard part of the Delphi programming environment. The earlier implementation of the Franklin algorithm for the generation of fractional design (Franklin, 1985) was written in FORTRAN by Turiel (1988). With the first step, the transformation of the FORTRAN code into Pascal, small improvements could be made. The first alteration concerned an improvement of the routine that searches for valid fractional designs. This improvement resulted in more valid solutions than did the Turiel implementation, but only under relatively rare conditions. A second improvement concerned the use of memory allocation: In some circumstances, the program needs less memory than was allocated in Turiel's original version. The program has a help file that explains the use and limitations of the program. It also offers a short introduction to fractional design, which may be helpful when the program's output is interpreted. There are many other sources for documentation, since an increasing number of books are published on the subject of fractional design (Box, Hunter, \& Hunter, 1978; Dodge, Fedorov, \& Wynn, 1988; Kempthorne, 1952/1973; Louviere, 1988; McLean \& Anderson, 1984; Upperman, 1993; Winer et al., 1991), some of them specifically written for use in the social sciences.

Interface. Before using the program, the researcher needs to know the number of levels and factors of the full design. In the first dialog window, the user specifies the number of levels and factors of the complete design. The basic specification of the full design requires that all factors have the same number of levels. The number of levels must to be a prime (i.e., 2, 3, 5, or 7).

In the second dialog window, the user enters the degree of fractionation, which determines the number of parts the full design is fractionated into. The degree of fractionation is always a negative power of the number of levels.
The number of possible fractions is dependent on the number of factors and the degree of fractionation. For instance, in a $3^{(5-1)}$ design, the basic full $3^{5}$ design with five factors of three levels each, needs at least 243 subjects, when each treatment or run is given to a subject. The fractional design is a reduction of $3^{-1}$, or one third. The three equivalent fractions each have 81 runs, requiring at least 81 subjects.

The third dialog window offers the choice between searching for a fractional design or recreating a known valid fractional design. The creation of a fractional design is systematic and is defined by a so-called defining contrast. The program can search for such a defining contrast, given the specified features of the design. Alternatively, when a defining contrast is found in a previous session, and the user wants to recreate the fractional design, the defining contrast can be entered and the program regenerates the fractional design.

In the fourth dialog window, the user can select the protected effects. Protected effects are effects that are not confounded with each other. In this dialog window, the user can specify the main effects and the two-factor interactions that have to be protected to make estimation possible. The default option is to have only the main effects protected (see Figure 1).

In the fifth dialog window, the program offers an option for handling the remaining unprotected effects. If there remains unprotected main or two-way interaction effects, it is possible to have these unconfounded with the protected effects. Alternatively, they will be confounded with the protected effects. Remaining unprotected effects can always be confounded with each other and with all higher order effects.

The sixth dialog window allows the user to select the so-called indicator factors. Indicator factors allow the program to run efficiently by avoiding search through redundant solutions. Each combination of indicator factors determines a unique set of defining contrasts that can be found. Each set of defining contrasts that can be found with a specific combination of indicator factors is similar to a set found with another combination of indicator factors.

In most cases, the default indicator factors offered will suffice. However, the indicator factors become relevant if the user is looking for a specific solution. The number of indicator effects, as well as the minimum number of effects necessary to define a contrast, is always the same as the degree of fractionation. Each of the indicator effects is a unique part of one of the effects in the defining contrast. When a specific solution is desired, a valid set of indicator factors can be found by eliminating all factors in the defining contrast that are not unique. For instance, when the defining contrast is $(1)=\mathrm{A} 1 * \mathrm{C} 1 * \mathrm{E} 1=\mathrm{B} 1 * \mathrm{D} 1 *$ $\mathrm{E} 1=\mathrm{A} 1 * \mathrm{~B} 1 * \mathrm{E} 1 * \mathrm{~F} 1$, the valid indicator factors for finding this solution are the set of $\mathrm{C} 1, \mathrm{D} 1$, and $\mathrm{F} 1$, since the other factors A1, B1, and E1 are part of more than one of the effects in the defining contrast. In this example, there is only one valid set of indicator factors for finding this defining contrast. In other cases, various sets of indicator factors can lead to the same valid solution. For in- 
Fractional Design W/izard 1.3

Select Protected Effects. Protected Effects are unconfounded with each other and are estimable under the assumption that higher effects are negligible.

Aorailable Effects:

$A 1^{x} B 1$
$A 1^{x} B 2$
$A 1^{x} D 1$
$A 1^{x} D 2$
$A 1^{x} \square 1$
$A 1^{x} \square 2$
$A 1^{x} E 1$
$A 1^{x} E 2$
$B 1^{x} \mathrm{C} 1$
$B 1^{x} \mathrm{C} 2$
$B 1^{x} \mathrm{D} 1$
$B 1^{x} \mathrm{D2}$
$B 1^{x} E 1$

Protected Effects:

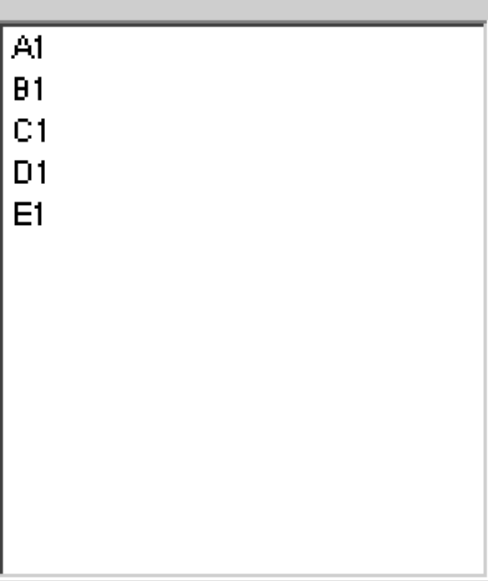

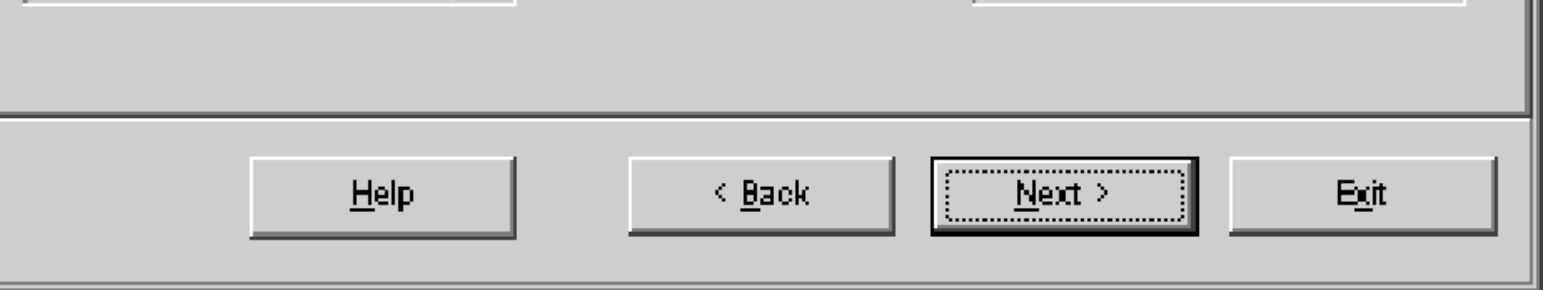
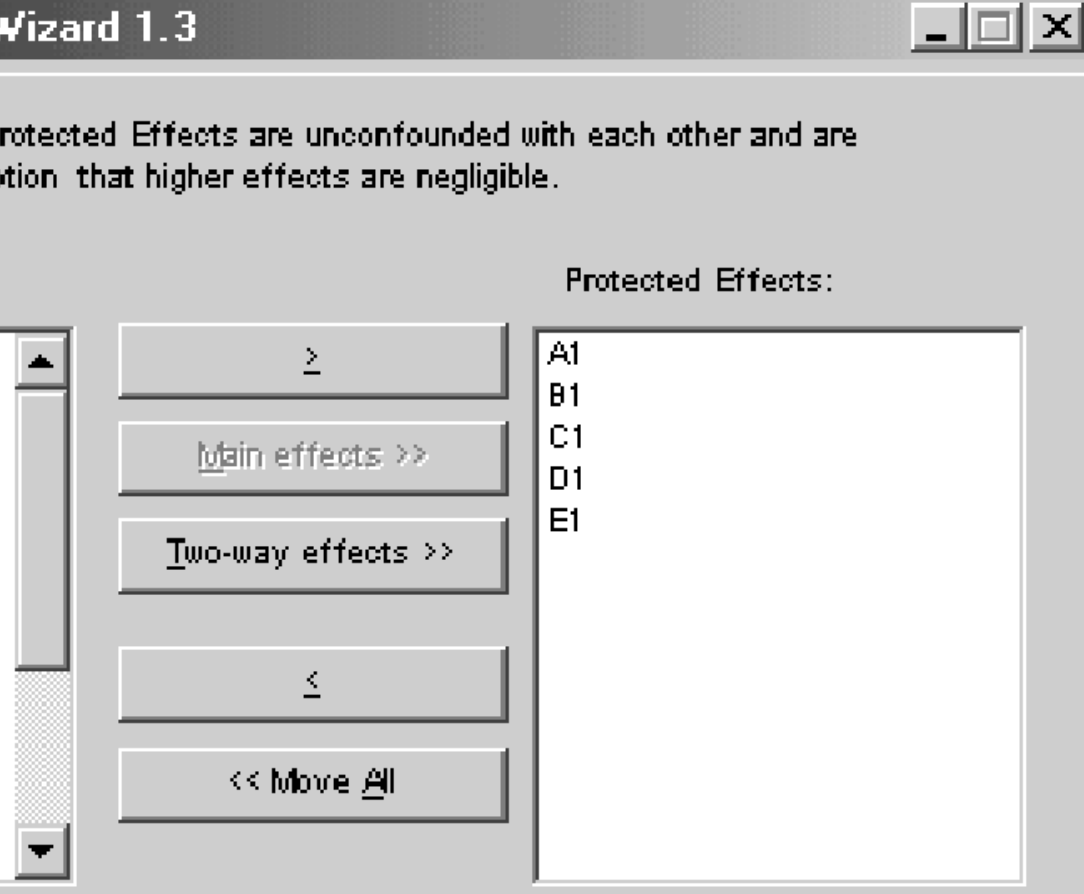

Figure 1: The fourth dialog window of Fractional Design Wizard. In this dialog window, the user selects the effects to be protected. A 3 $3^{(5-1)}$ fractional design is shown with the default option for the protected effects: All main effects are protected. The user can go forward to the next dialog window, or backward to the previous dialog window, using the Next button or the Back button.

stance, for a $2^{(6-2)}$ design, the solution $(1)=\mathrm{A} 1 * \mathrm{~B} 1 *$ $\mathrm{C} 1 * \mathrm{E} 1=\mathrm{A} 1 * \mathrm{~B} 1 * \mathrm{D} 1 * \mathrm{~F} 1$ can be found with indicator factor pairs $\mathrm{C} 1$ and $\mathrm{D} 1, \mathrm{C} 1$ and $\mathrm{F} 1, \mathrm{E} 1$ and D1, and E1 and F1. When this specific solution is searched for, the nonunique factors $\mathrm{A} 1$ and $\mathrm{B} 1$ cannot be used as indicator factors. Franklin (1985) offers a more technical description of the use of indicator effects.

The seventh dialog window is for selecting the output. The user can select the desired output for display. The last dialog window is the output window. The user can select, copy and paste the output for use in other programs, print it, or save it as a text file.

Although the user needs a basic knowledge of common experimental designs, the program and accompanying help file provide the user with the necessary information for each of the dialog windows. However, the help file is no more than a short introduction to the field. Advanced work on fractional design (e.g., Upperman, 1993) offers solutions for fractional designs in complicated situations not covered by the program.

Output. First, the output (see the Appendix for examples) shows the chosen design parameters: number of lev- els, number of factors, and degree of fractionation. Second, it shows the selected protected effects that are unconfounded with each other and, when so chosen, the effects that are unconfounded with the protected effects. Further, the selected indicator factors are also shown. When the program finds a suitable solution for these design parameters, the group formed by the defining contrasts and the first and the defining contrast is optionally displayed. The defining contrast is the information needed to recreate the fractional design. Optionally, the full pattern of confounding is displayed. This information is needed to interpret the results of an ANOVA, when fractional design is used. If the presented solution is satisfactory, the user may want to display the fractions. Each fraction shows the runs (or experimental treatments) necessary to implement the fraction. In the Appendix, four examples of output are presented. These examples are the same as those offered by Turiel (1988).

The output answers several key questions. If the program can find a solution, given the chosen design parameters, the output provides the information needed to implement the design, as well as the information needed to interpret 
the output of an ANOVA of the results obtained by using the fractional design.

\section{Evaluation}

The intended goal of this project was to make fractional design more easily available to social science researchers. The first stage in the process was the construction of the step-by-step user interface, offering the user the opportunity to make decisions concerning the design without the distraction of unnecessary information or further requirements. The second stage was the construction of a help file, which provides the information needed for using the program, as well as a basic introduction to fractional design.

The easy-to-use interface is an important improvement in comparison with older, as well as more recent, programs. Nevertheless, further improvements are possible. The search algorithm is not very fast and could be improved. The designs the program can handle are limited to fractional designs with factors of two, three, five, and seven levels. Upperman (1993) pointed to possible solutions for factors of four levels, which may be augmented to six and eight levels. An ANOVA of these fractional designs with a nonprime number of levels needs special provisions, and interpretation of results obtained with these designs may be less than straightforward. The present program does not offer solutions for mixed designs that use a different number of levels for each of the factors. Again, Upperman showed some possible solutions. Further research is needed, aimed at improving search-and-select mechanisms for possible fractional designs, for the implementation of more complex fractional designs. Furthermore, an ANOVA should be made available for designs of factors with more than three levels and involving protected two-way interactions. Regular ANOVAs are not suited to these situations.

Notwithstanding these possible improvements, we think that the present program makes fractional design more accessible to behavioral researchers and can prevent some of the possible misunderstandings and misinterpretations of fractional designs.

\section{Availability}

Our primary goal is to make fractional design more easily available to researchers in the social sciences and to offer the possibility of learning about fractional design in an easy way. Therefore, the program is made available as freeware and is distributed via the Internet at www.fss. uu.nl/ms/hl/fracdes.htm.

\section{REFERENCES}

Berger, P. D., \& Magliozzi, T. L. (1993). Experimental design in direct mail and the application of Taguchi methods. Journal of Direct Marketing, 7, 44-55.

Box, G. E. P., Hunter, W. G., \& Hunter, J. S. (1978). Statistics for experimenters. New York: Wiley.

Cestre, G., \& Darmon, R. Y. (1998). Assessing consumer preferences in the context of new product diffusion. International Journal of Research in Marketing, 13, 139-161.

Cochran. W. G., \& Cox, G. M. (1957). Experimental designs. New York: Wiley.

CONNOR, W. S., \& ZELEN, M. (1959). Fractional factorial experiment designs for factors at three levels (Applied Mathematics Series No. 54). Washington, DC: U.S. Government Printing Office.

DeY, A. (1985). Orthogonal fractional factorial designs. New York: Wiley. Dodge, Y., Fedorov, V. V., \& WYNn, H. P. (1988). Optimal design of experiments: An overview. In Y. Dodge, V. V. Fedorov, \& H. P. Wynn (Eds.), Optimal design and analysis of experiments. Amsterdam: NorthHolland.

FranKLIN, M. F. (1985). Selecting defining contrasts and confounded effects in $p^{n-m}$ factorial experiments. Technometrics, 27, 165-172.

KAUL, A., \& RAO, C. (1995). Research for product positioning and design decisions: An integrative review. International Journal of Research in Marketing, 12, 293-320.

Kempthorne, O. (1973). The design and analysis of experiments. Huntington, WV: Krieger. (Original work published 1952)

KIRK, L. K. (1993). Confounded factorial designs. In L. K. Edwards (Ed.), Applied analysis in behavioral science (pp. 197-253). New York: Marcel Dekker.

Landsheer, J. A., \& VAn den Wittenboer, G. (2000). Fractional designs: A simulation study of usefulness in the social sciences. Behavior Research Methods, Instruments, \& Computers, 32, 528-536.

Louviere, J. J. (1988). Analyzing decision making: Metric conjoint analysis. Newbury Park, CA: Sage.

McLean, R. A., \& ANDERSON, V. L. (1984). Applied factorial and fractional designs. New York: Marcel Dekker.

MendenhalL, W. (1968). Introduction to linear models and the design and analysis of experiments. Belmont, CA: Wadsworth.

Mesenbrink, P., \& LU, J. C. (1994). Characterization and optimization of a wave-soldering process. Journal of the American Statistical Association, 89, 1209-1218.

Nachtheim, C. J. (1987). Tools for computer-aided design of experiments. Journal of quality control, 19, 132-160.

SPSS (1997). Trial Run 1.0 user's guide. Chicago: SPSS Incorporated. TURIEL, T. P. (1988). A FORTRAN program to generate fractional factorial experiments. Journal of Quality Technology, 20, 63-72.

UPPERMAN, P. M. (1993). Designs with a small number of runs for factorial experiments. Unpublished doctoral dissertation, Technical University of Eindhoven.

Winer, B. J., Brown, D. R., \& Michels, K. M. (1991). Statisticalprinciples in experimental design (3rd ed.). New York: McGraw-Hill.

\section{APPENDIX \\ Output Examples}

These examples are the same as those offered by Turiel (1988). The output differs from the output presented by Turiel in one respect: Turiel showed nonunique factors [such as A1 next to A2, which are actually the same $(\mathrm{A} 1=\mathrm{A} 2)$ ], whereas the present program displays only unique factors. Another difference is that the current program offers the full pattern of confounded factors, which may be helpful when results are interpreted. The designs with two levels for each factor have the factor level coded with 0 or 1 for every run. When there are three levels, the codes for the levels are 0,1 , and 2 for every run. 


\section{APPENDIX (Continued)}

\section{Output Listing 1}

This design is the same as the solution presented by Dey (1985) for a four-factor experiment in which each factor has three levels. The full $3^{4}$ design requires 81 runs. The program searches for a $1 / 3$ fraction of the full design - that is, a $3^{(4-1)}$ design. The remaining unprotected effects may be confounded only with each other and with higher order interaction effects. The solution is found with indicator factor D1, but can also be found with indicator factor $\mathrm{C} 1, \mathrm{~B} 1$, or $\mathrm{A} 1$.

Design Parameters:

Number of Levels: 3

Number of Factors: 4

Degree of Fractionation: 1

Design: $3 \wedge(4-1)$ resulting in three fractions of 27 runs.

Protected effects that are unconfounded with each other:

(1)

A1

B1

$\mathrm{C} 1$

D1

Effects unconfounded with the protected effects:

$\mathrm{A} 1 * \mathrm{~B} 1$

$\mathrm{A} 1 * \mathrm{~B} 2$

$\mathrm{A} 1 * \mathrm{C} 1$

$\mathrm{A} 1 * \mathrm{C} 2$

$\mathrm{A} 1 * \mathrm{D} 1$

$\mathrm{A} 1 * \mathrm{D} 2$

$\mathrm{B} 1 * \mathrm{C} 1$

$\mathrm{B} 1 * \mathrm{C} 2$

$\mathrm{B} 1 * \mathrm{D} 1$

$\mathrm{B} 1 * \mathrm{D} 2$

$\mathrm{C} 1 * \mathrm{D} 1$

$\mathrm{C} 1 * \mathrm{D} 2$

Indicator Factors: D1

A defining contrast is:

(1) $=\mathrm{A} 1 * \mathrm{~B} 1 * \mathrm{C} 1 * \mathrm{D} 1$

Confounded effects:

(1) $=\mathrm{A} 1 * \mathrm{~B} 1 * \mathrm{C} 1 * \mathrm{D} 1$

$[\mathrm{A} 1]=\mathrm{B} 1 * \mathrm{C} 1 * \mathrm{D} 1=\mathrm{A} 1 * \mathrm{~B} 2 * \mathrm{C} 2 * \mathrm{D} 2$

$[\mathrm{B} 1]=\mathrm{A} 1 * \mathrm{C} 1 * \mathrm{D} 1=\mathrm{A} 1 * \mathrm{~B} 2 * \mathrm{C} 1 * \mathrm{D} 1$

$[\mathrm{A} 1 * \mathrm{~B} 1]=[\mathrm{C} 1 * \mathrm{D} 1]=\mathrm{A} 1 * \mathrm{~B} 1 * \mathrm{C} 2 * \mathrm{D} 2$

$[\mathrm{A} 1 * \mathrm{~B} 2]=\mathrm{A} 1 * \mathrm{C} 2 * \mathrm{D} 2=\mathrm{B} 1 * \mathrm{C} 2 * \mathrm{D} 2$

$[\mathrm{C} 1]=\mathrm{A} 1 * \mathrm{~B} 1 * \mathrm{D} 1=\mathrm{A} 1 * \mathrm{~B} 1 * \mathrm{C} 2 * \mathrm{D} 1$

$[\mathrm{A} 1 * \mathrm{C} 1]=[\mathrm{B} 1 * \mathrm{D} 1]=\mathrm{A} 1 * \mathrm{~B} 2 * \mathrm{C} 1 * \mathrm{D} 2$

$[\mathrm{B} 1 * \mathrm{C} 1]=[\mathrm{A} 1 * \mathrm{D} 1]=\mathrm{A} 1 * \mathrm{~B} 2 * \mathrm{C} 2 * \mathrm{D} 1$

$\mathrm{A} 1 * \mathrm{~B} 1 * \mathrm{C} 1=[\mathrm{D} 1]=\mathrm{A} 1 * \mathrm{~B} 1 * \mathrm{C} 1 * \mathrm{D} 2$

$\mathrm{A} 1 * \mathrm{~B} 2 * \mathrm{C} 1=[\mathrm{B} 1 * \mathrm{D} 2]=\mathrm{A} 1 * \mathrm{C} 1 * \mathrm{D} 2$

$[\mathrm{A} 1 * \mathrm{C} 2]=\mathrm{B} 1 * \mathrm{C} 2 * \mathrm{D} 1=\mathrm{A} 1 * \mathrm{~B} 2 * \mathrm{D} 2$

$[\mathrm{B} 1 * \mathrm{C} 2]=\mathrm{A} 1 * \mathrm{~B} 2 * \mathrm{D} 1=\mathrm{A} 1 * \mathrm{C} 2 * \mathrm{D} 1$

$\mathrm{A} 1 * \mathrm{~B} 1 * \mathrm{C} 2=\mathrm{A} 1 * \mathrm{~B} 1 * \mathrm{D} 2=[\mathrm{C} 1 * \mathrm{D} 2]$

$\mathrm{A} 1 * \mathrm{~B} 2 * \mathrm{C} 2=[\mathrm{A} 1 * \mathrm{D} 2]=\mathrm{B} 1 * \mathrm{C} 1 * \mathrm{D} 2$

At least one of the main effects is confounded with three-way effect $(\mathrm{s})$

At least one of the two-way effects is confounded with two-way effect (s)

To run the defined experiment, use one of the following fractions:

Fraction 1

Run a b c d

$\begin{array}{llllll}1 & 0 & 0 & 0 & 0\end{array}$

$2 \quad 2 \quad 1 \quad 0 \quad 0$

$\begin{array}{llllll}3 & 1 & 2 & 0 & 0\end{array}$ 


\section{APPENDIX (Continued)}

$\begin{array}{lllll}4 & 2 & 0 & 1 & 0 \\ 5 & 1 & 1 & 1 & 0 \\ 6 & 0 & 2 & 1 & 0 \\ 7 & 1 & 0 & 2 & 0 \\ 8 & 0 & 1 & 2 & 0 \\ 9 & 2 & 2 & 2 & 0 \\ 10 & 2 & 0 & 0 & 1 \\ 11 & 1 & 1 & 0 & 1 \\ 12 & 0 & 2 & 0 & 1 \\ 13 & 1 & 0 & 1 & 1 \\ 14 & 0 & 1 & 1 & 1 \\ 15 & 2 & 2 & 1 & 1 \\ 16 & 0 & 0 & 2 & 1 \\ 17 & 2 & 1 & 2 & 1 \\ 18 & 1 & 2 & 2 & 1 \\ 19 & 1 & 0 & 0 & 2 \\ 20 & 0 & 1 & 0 & 2 \\ 21 & 2 & 2 & 0 & 2 \\ 22 & 0 & 0 & 1 & 2 \\ 23 & 2 & 1 & 1 & 2 \\ 24 & 1 & 2 & 1 & 2 \\ 25 & 2 & 0 & 2 & 2 \\ 26 & 1 & 1 & 2 & 2 \\ 27 & 0 & 2 & 2 & 2 \\ <\text { two } & \text { more }\end{array}$

\section{Output Listing 2}

This concerns plan 6A.4 of Cochran and Cox (1957). This design is a one-eighth fraction of a $2^{6}$ factorial design, in which all main effects and the $\mathrm{AB}$ interaction are protected and therefore estimable. However, the protected effects are allowed to be confounded with the remaining two-way interactions. For every set of indicator factors, two valid solutions are found. However, since the desired solution is $(1)=\mathrm{A} 1 * \mathrm{C} 1 * \mathrm{E} 1=$ $\mathrm{B} 1 * \mathrm{D} 1 * \mathrm{E} 1=\mathrm{A} 1 * \mathrm{~B} 1 * \mathrm{E} 1 * \mathrm{~F} 1$, the indicator factors must be $\mathrm{C} 1, \mathrm{D} 1$, and $\mathrm{F} 1$. In contrast to Turiel's (1988) implementation, the user can select this third set of indicator factors $(\mathrm{C} 1, \mathrm{D} 1, \mathrm{~F} 1)$ as one of the offered choices. In Turiel's program, the user has to try for another solution, until the desired solution is found.

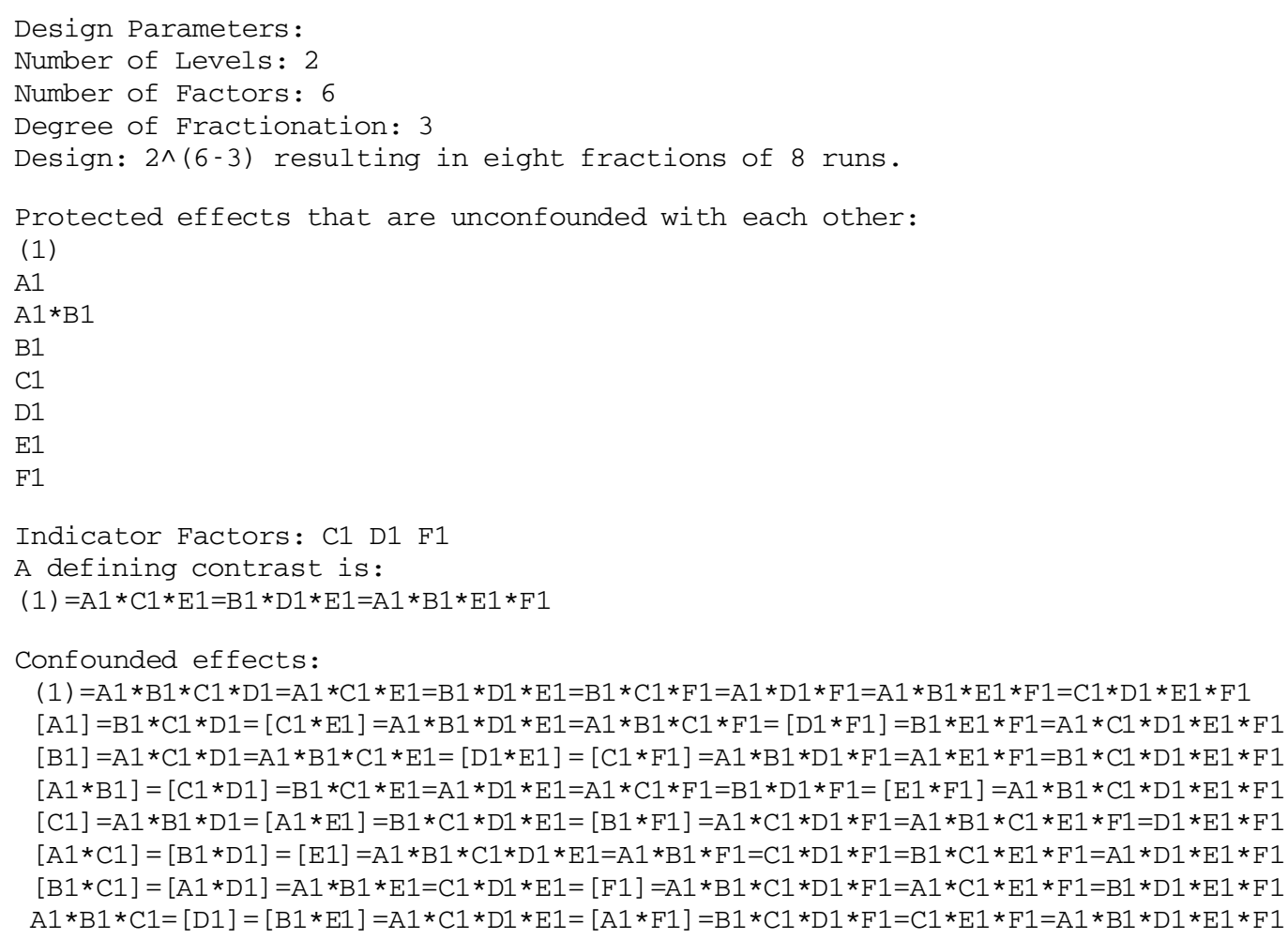




\section{APPENDIX (Continued)}

At least one of the main effects is confounded with two-way effect (s)

At least one of the two-way effects is confounded with main effect (s)

To run the defined experiment, use one of the following fractions:

Fraction 1

Run a b c d e $\mathrm{f}$

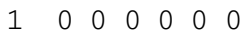

$2 \quad 1 \quad 1111100$

$\begin{array}{llllllllll}3 & 0 & 1 & 1 & 0 & 1 & 0\end{array}$

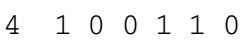

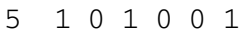

$6 \begin{array}{lllllll}6 & 0 & 1 & 0 & 1 & 0 & 1\end{array}$

$\begin{array}{lllllll}7 & 1 & 1 & 0 & 0 & 1 & 1\end{array}$

$8 \begin{array}{llllllllll}8 & 0 & 0 & 1 & 1 & 1 & 1\end{array}$

$<$ The program generates seven other fractions >

\section{Output Listing 3}

The third example shows a regeneration of a known defining contrast. It is the solution offered by the National Bureau of Standards (Connor \& Zelen, 1959), involving four factors with three levels each. The main effects and the interaction effects A1B2, A1C2, A1D2, B1C2, B1D2, and C1D2 are estimable. The protected effects are allowed to be confounded with the remaining unprotected two-way interactions. The indicatorfactor in this example is D1. However, the same solutions can be found with indicator factor A1, B1, or C1.

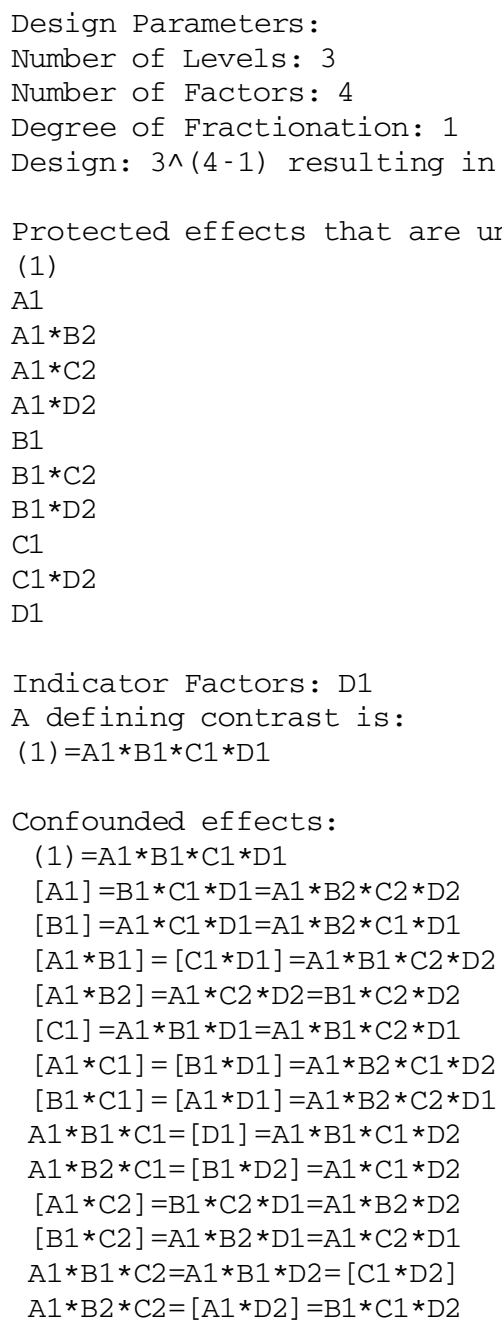




\section{APPENDIX (Continued)}

At least one of the main effects is confounded with three-way effect(s)

At least one of the two-way effects is confounded with two-way effect(s)

To run the defined experiment, use one of the following fractions:

Fraction 1

Run a b c d

$\begin{array}{llllll}1 & 0 & 0 & 0 & 0\end{array}$

$\begin{array}{lllll}2 & 2 & 1 & 0 & 0\end{array}$

$\begin{array}{lllll}3 & 1 & 2 & 0 & 0\end{array}$

$\begin{array}{lllll}4 & 2 & 0 & 1 & 0\end{array}$

$5 \quad 111110$

$\begin{array}{lllll}6 & 0 & 2 & 1 & 0\end{array}$

$\begin{array}{lllll}7 & 1 & 0 & 2 & 0\end{array}$

$\begin{array}{lllll}8 & 0 & 1 & 2 & 0\end{array}$

$9 \quad 2 \quad 2220$

$\begin{array}{lllll}10 & 2 & 0 & 0 & 1\end{array}$

$\begin{array}{lllll}11 & 1 & 1 & 0 & 1\end{array}$

$\begin{array}{lllll}12 & 0 & 2 & 0 & 1\end{array}$

$\begin{array}{lllll}13 & 1 & 0 & 1 & 1\end{array}$

$\begin{array}{lllll}14 & 0 & 1 & 1 & 1\end{array}$

$\begin{array}{lllll}15 & 2 & 2 & 1 & 1\end{array}$

$\begin{array}{lllll}16 & 0 & 0 & 2 & 1\end{array}$

$\begin{array}{lllll}17 & 2 & 1 & 2 & 1\end{array}$

$\begin{array}{lllll}18 & 1 & 2 & 2 & 1\end{array}$

$\begin{array}{lllll}19 & 1 & 0 & 0 & 2\end{array}$

$\begin{array}{lllll}20 & 0 & 1 & 0 & 2\end{array}$

$\begin{array}{lllll}21 & 2 & 2 & 0 & 2\end{array}$

$\begin{array}{lllll}22 & 0 & 0 & 1 & 2\end{array}$

$\begin{array}{lllll}23 & 2 & 1 & 1 & 2\end{array}$

$\begin{array}{lllll}24 & 1 & 2 & 1 & 2\end{array}$

$\begin{array}{lllll}25 & 2 & 0 & 2 & 2\end{array}$

$\begin{array}{lllll}26 & 1 & 1 & 2 & 2\end{array}$

$\begin{array}{lllll}27 & 0 & 2 & 2 & 2\end{array}$

$<$ The program generates two other fractions >

\section{Output Listing 4}

The last example is based on the solution presented by Box, Hunter, and Hunter (1978) and demonstrates that the program finds the same solution for the $2^{(5-1)}$ design. All two-way interaction effects are protected, and there are no remaining unprotected main or two-way interaction effects. The solution is found with indicator factor E1, but the same solution can be found with indicator factor D1, C1, B1, or A1.

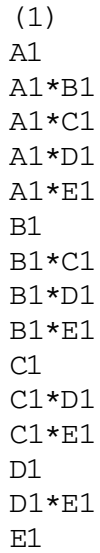


APPENDIX (Continued)

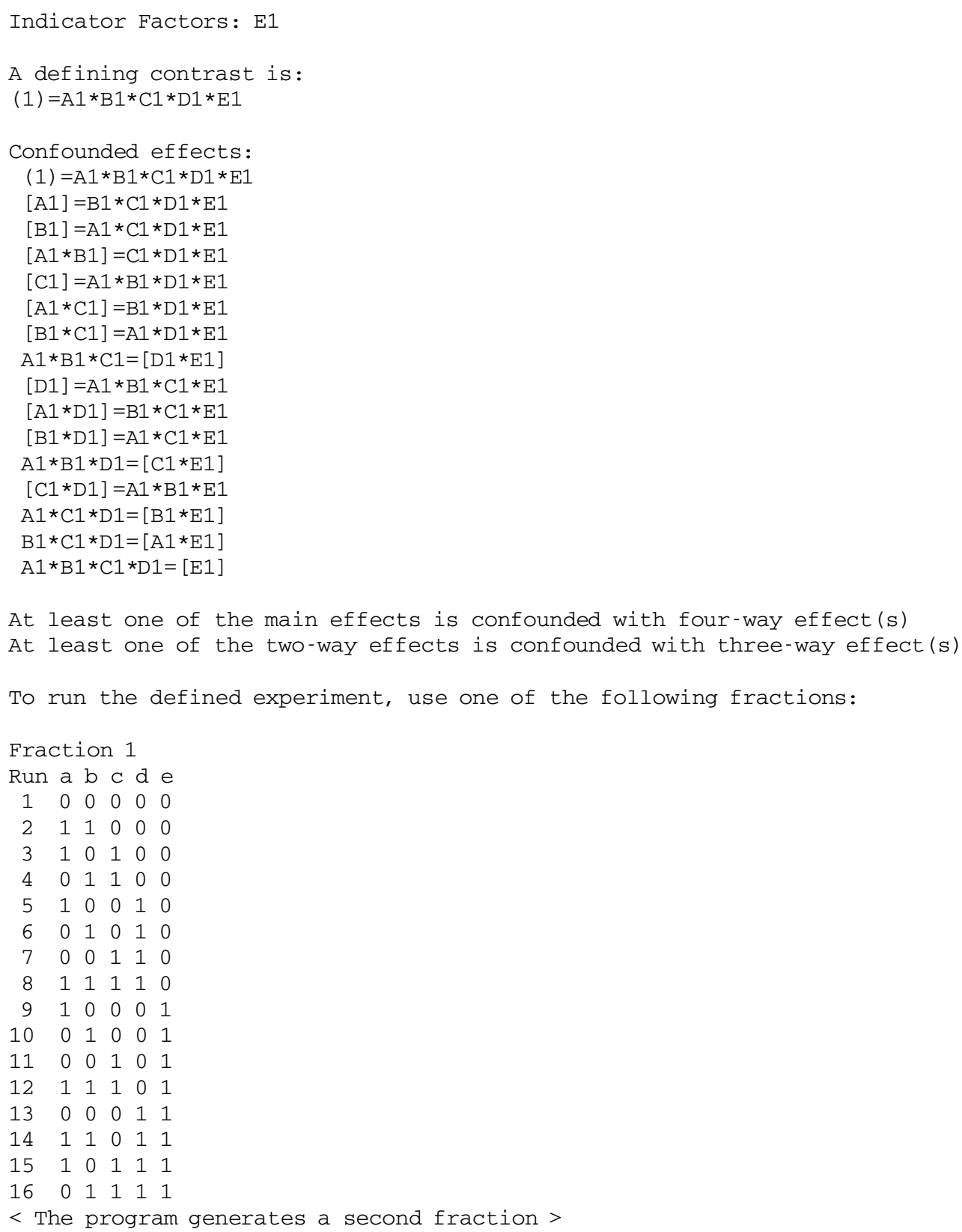

(Manuscript received January 2, 2001;

revision accepted for publication August 17, 2001.) 